Article

\title{
Effect of Xylo-Oligosaccharides Supplementation by Drinking Water on the Bone Properties and Related Calcium Transporters in Growing Mice
}

\author{
Hang Gao and Zhenlei Zhou * \\ College of Veterinary Medicine, Nanjing Agricultural University, Nanjing 210095, China; \\ 2019207053@njau.edu.cn \\ * Correspondence: zhouzl@njau.edu.cn; Tel.: +86-25-8439-5505
}

Received: 25 October 2020; Accepted: 17 November 2020; Published: 19 November 2020

\begin{abstract}
Xylo-oligosaccharides (XOS), non-digestible oligosaccharides, have the potential to regulate intestinal microorganisms, and thus, improve host health, but little evidence exists for the prebiotic effects on bone health. This study evaluates the dose-response effect of XOS supplementation on bone properties, the morphology of the intestine, cecum $\mathrm{pH}$, and cecum wall weight, as well as the related calcium transporters. Ninety-six 28-day-old male mice were randomized into one of four groups, fed the same commercial diet, and given different types of deionized water containing $0,1,2$, or $4 \%$ XOS by concentration for 30 days. Eight mice were randomly selected to accomplish particular tasks every 10 days. No significant differences in serum $\mathrm{Ca}$ and $\mathrm{P}$ levels and growth performance were observed among the four studied groups. XOS intervention significantly decreased cecum $\mathrm{pH}$ and increased cecum wall weight in a dose-dependent manner. At the late growth stage, compared with $0 \%$ XOS, the bone mineral density (BMD) and bone-breaking strength in $4 \%$ XOS were significantly higher. The bone crystallinity with $4 \%$ XOS, measured by Raman spectrum, was significantly enhanced compared to that with $0 \%$ XOS during later growth. The villus height and villus height to crypt depth (VH:CD) were enhanced with an increase of XOS concentration during the later stage of growth. The expression of transient receptor potential vanillin receptor 6 (TRPV6) and $\mathrm{Na}^{+} / \mathrm{Ca}^{2+}$ exchanger 1 (NCX1) in the duodenum were enhanced by XOS supplementation. XOS exerted a positive influence on bone properties by decreasing the cecum $\mathrm{pH}$, increasing the cecum wall and villus structure, and upregulating the expression of related calcium transporters.
\end{abstract}

Keywords: xylo-oligosaccharides; bone properties; calcium transporters; growing mice

\section{Introduction}

One approach to reducing the risk of osteoporosis later in life for children and adolescents is to ensure the development of ideal peak bone mass and bone strength during growth [1]. Any enhancement in calcium (Ca) absorption during childhood and adolescence may ultimately increase bone retention, which will help achieve optimal peak bone mass. The supplementation of dietary calcium from milk and dairy products is the main source of Ca. Ca supplementation in tablet form is also one of the basic measures. At present, the public prefers to focus on the functional ingredients that improve $\mathrm{Ca}$ absorption [2]. Functional oligosaccharides, also known as non-digestible oligosaccharides (NDOs), are currently considered the most promising prebiotics for improving bone health [3-5]. Examples of these non-digestible carbohydrates include galactooligosaccharide (GOS), fructooligosaccharide (FOS), human milk oligosaccharides (HMO), isomaltose oligosaccharides, xylo-oligosaccharides (XOS), and inulin. The non-digestibility of NDOs in the gastrointestinal tract is due to resistance to gastric acid, mammalian hydrolases, and gastrointestinal absorption. After undergoing fermentation by the intestinal microbiota, NDOs selectively stimulate either 
the growth or the activity of gut microbiota with demonstrable benefits for host health [6]. The main nutritional role of NDOs is to produce a direct physiological effect on the host, including anti-inflammation, antioxidation, mineral metabolism, lipid metabolism, and immune modulation [3,4,7-9].

XOS is a kind of emergent prebiotic composed of 2-7 xylose molecules with $\beta-1,4$ glycoside bond [10], which are naturally found in fruits, vegetables, milk, and honey [11]. XOS supplementation has shown significant prebiotic activities in humans, broilers, laying hens, and weaned piglets by modulating the gut microbiota [12-14]. Presently, XOS is widely used in health care, dairy beverages, and the food and feed industries. However, people currently attach great importance to XOS, mainly because of its unique effects on enhancing animal disease resistance, stimulating the immune system of animal bodies, and improving a number of chronic, inflammatory conditions. Compared with other NDOs, such as GOS, FOS, and inulin, few data about XOS are available that support the evidence of mineral metabolism and bone health in an animal model [15]. One of these studies reported that the probiotics L. paracasei HII01, XOS, or both together as a biotic therapy produced similar potential enhancement of bone microarchitecture in rats fed a high-fat diet (HFD), possibly by mitigating osteoclast-mediated bone resorption and promoting osteoblast-induced bone formation [16]. In addition, previous research into dietary XOS on bone mineral crystallinity in swine femurs suggested that XOS enhances the crystallinity of bone and that the effects of XOS on femurs may be more obvious during periods of early growth, while this influence was not observed in bones sampled during later growth [17]. These studies suggest that XOS may be involved in the absorption of minerals and improving bone health. Currently, there are two widely accepted mechanisms used to explain NDO-bone interactions: (1) The production of short-chain fatty acids (SCFAs) in the lower gut by intestinal microorganism fermentation and (2) a change in the microbial community composition. It is also worth considering the changes in tissue morphology and mineral transporter proteins. Moreover, few reports about inulin, lactose, and other prebiotic NDOs have indicated their molecular mechanisms of mineral absorption [18-20].

The majority of the literature supporting the effects of prebiotics on bone comes from animal research. Hence, rodent models are imperative for understanding the direct contributions of the XOS-induced changes to the prebiotic effects at the level of bone health. The aim of this study was to determine, in growing mice, the effects of XOS provided by water on bone-relevant parameters and the expression of related calcium transporters using methods of biomechanics, Raman spectroscopy, and immunohistochemistry. We hypothesize, through a rodent modeling analysis, that XOS enhances bone properties and can be used as an adjuvant therapy to achieve peak bone mass in the growing period.

\section{Materials and Methods}

\subsection{Animals, Diets, and Experimental Design}

Ninety-six 21-day-old weanling male Institute Cancer Research (ICR) mice (20-22 g) were purchased from Qinglongshan Animal Breeding Farm in Nanjing. They were housed in individual stainless-steel cages under standardized environmental conditions $\left(22 \pm 1^{\circ} \mathrm{C}\right.$, the relative humidity of $50 \%$, on a $12 \mathrm{~h}$ light/dark cycle) in the Nanjing Agricultural University animal facility. After a 7days adaptation period, ninety-six 28-day-old mice were randomly assigned to the four studied groups to receive one of the four types of experimental drinking water until 58 days of age. All groups were fed the same commercial cereal-based diet (Qinglongshan Feed Production Co., Ltd., Nanjing, China; containing $18 \%$ crude protein, $5 \%$ crude fiber, $4 \%$ crude fat, $8 \%$ crude ash, $1.0 \% \mathrm{Ca}, 0.6 \% \mathrm{P}$, and $5.3 \%$ methionine and cysteine), and XOS (95\% XOS, Longlive Bio-Technology Co., Ltd., Dezhou, China) was given at concentrations of $0,2.1,4.2$, and $8.4 \mathrm{~g}$ for every $200 \mathrm{~mL}$ of deionized water $(1.0 \%$ XOS group, control group; $2.1 \%$ XOS group; 3.2\% XOS group, and 4.4\% XOS group). The whole experiment lasted 30 days, and during this period, eight mice from each group were randomly selected to accomplish particular tasks every 10 days $(n=8)$. The bodyweight and food intake were recorded once every 10 days. The experimental drinking water was recorded every day. Throughout the entire experimental period, all mice had free access to food and experimental drinking water. Food efficiency ratios (FERs) 
for the experimental period were calculated by the bodyweight gain divided by food intake, and signs of health were observed daily. However, no adverse events or mortality occurred during the trial.

All animal maintenance, handling, and procedures were performed in accordance with the National Institutes of Health guidelines for the care and use of laboratory animals and were approved by the ethical committee at Nanjing Agricultural University (Approved number NJAU-VM-2018009).

\subsection{Sample Collection}

At 38,48 , and 58 days of age, eight mice without food and water for 8hours from each group were randomly selected and euthanized with a $\mathrm{CO}_{2}$ overdose to accomplish many tasks. Fasting blood samples were collected from the retro-orbital venous plexus before sacrifice, and the serum samples were stored at $-20{ }^{\circ} \mathrm{C}$ until the analyses were performed. Cecum $\mathrm{pH}$ was measured directly by a $\mathrm{pH}$ meter (SX-620, Sanxin, Shanghai), and the cecum contents were removed. The cecum wall was then flushed with $0.9 \%$ saline, blotted dry with filter paper, and weighed. The duodenum was separated and stored in $4 \%$ formaldehyde for histology and semi-quantitative immunohistochemistry. Femurs were excised and cleaned of their muscle tissue and stored at $-20^{\circ} \mathrm{C}$ for later bone properties analyses.

\subsection{Determination of Serum Calcium and Phosphorus}

The calcium and phosphorus $(\mathrm{P})$ concentration in serum was evaluated through habitual methods using an automated analyzer (Bs-300, Mindray Biomedical Electronics Co., Ltd., Shenzhen, China).

\subsection{Determination of Femur Biological Parameters}

The left femurs were removed from $-20^{\circ} \mathrm{C}$ and thawed overnight at $4{ }^{\circ} \mathrm{C}$. Bone growth parameters included length and diameter (middle axis of bone) were measured in millimeters by vernier caliper, and bone weight was measured in grams by the precision electronic scale.

The dried left femur samples were placed in the center of the stage, bone mineral density (BMD) and bone mineral content (BMC) were measured by dual-energy X-ray absorptiometry (DEXA; InAlyzer, Medikors, Korea), after the calibration of the instrument. All femur samples were scanned using identical scan parameters $(55 \mathrm{kVp} / 1.25 \mathrm{~mA} \sim 80 \mathrm{kVp} / 1.0 \mathrm{~mA})$ and placed in the same position. After scanning, a digital image analysis system (InAlyzer1.0, Korea) was used to analyze the achieved image. Then, different subareas were analyzed on the image of the femur on the screen using a region of interest (ROI) for each segment. Finally, the pictures and data were saved.

The widths of Raman peaks are often used to evaluate bone mineral crystallinity. Raman microprobe spectroscopy (ThemoFisher DXR532, Madison, WI, USA) was performed on the middle part of the cross-section (sawn across the mid-shaft) of the left femur. Some relevant parameter settings are as follows: The spectral region, 400-1800/cm; laser, $532 \mathrm{~nm}$; laser power, $10 \mathrm{~mW}$. Raman analysis of each sample was performed three times (three different spots). The peak positions were calibrated with a silicon wafer $(520.5 / \mathrm{cm})$. All Raman spectra were acquired through the typical acquisition of the $4 \times 4 \mathrm{~s}$ per analysis spot using an LMPlan 20× objective (Olympus, Inc., Tokyo, Japan). The data were analyzed with the Labspec 5 software.

Lastly, the breaking strength at the midpoint of each left femur was determined by a three-point bending test using a material testing machine (LR10K PLUSLloyd Instruments Ltd., Bognor Regis, UK). The load was applied vertically to the long axis at the mid-length region of the femur (displacement rate of $15 \mathrm{~mm} / \mathrm{min}$, preload of $5 \mathrm{~N}$ ). The distance between the supporting points was $8 \mathrm{~mm}$. Once the femur sample broke, the machine was stopped, and then a compression curve appeared on the screen. The compression curve was analyzed and processed with the NEXYGEN PLUS software. The highest value of the curve was the bone-breaking strength $(\mathrm{N})$ of the test sample. The data were then recorded.

\subsection{Gut Morphology and Immunohistochemistry Analysis}

After euthanization, a $2 \mathrm{~cm}$ segment was removed from the duodenum, washed in a physiological saline solution, and fixed in $4 \%$ formaldehyde for $24 \mathrm{~h}$. Then, the samples were dehydrated through 
consecutive embedding in graded ethanol solutions. Thereafter, the fixed samples were embedded in paraffin. Transverse and longitudinal sections $5 \mu \mathrm{m}$ in thickness were prepared using a microtome stained with hematoxyline-eosin. Finally, the prepared tissue slices were used for morphological observations. Villus height and crypt depth were examined under a light microscope (OLYMPUS DP71, BX50F-3, Olympus Optical Co. Ltd., Tokyo, Japan). The examinations were made under a 40× lens, all measurements were obtained using 15 villi per slide, and the mean values of 2 slides per pen were used for statistical analysis.

Five-micron-thick tissue sections from another $2 \mathrm{~cm}$ duodenum segment were deparaffinized in xylene and rehydrated in a descending series of ethanol in distilled water. The tissue sections were treated with 3\% hydrogen peroxide methanol solution for $15 \mathrm{~min}$, followed by three 5 min rinses with phosphate-buffered saline. Then, the sections were blocked with $10 \%$ normal goat serum for $40 \mathrm{~min}$ at room temperature. The sections were incubated overnight at $4{ }^{\circ} \mathrm{C}$ with either anti-rat matrix transient receptor potential vanillin receptor 6 (TRPV6) $(1: 500 ; 15506 \mathrm{R}$ from Bioss, Beijing, China) or anti-rat matrix $\mathrm{Na}^{+} / \mathrm{Ca}^{2+}$ exchanger 1 (NCX1) (1:1000; ab2869 from Abcam, Cambridge, UK). The color was developed by incubation in DAB (ZSGB-BIO, Beijing, China). The sections were counter-stained with hematoxylin. All sections were semi-quantitatively analyzed using Image-Pro Plus. The average optical density (AOD) was determined by the ratio of integrated optical density (IOD) to the area (region of interest) in three pictures for each sample.

\subsection{Statistical Analysis}

Data were analyzed using SPSS version 20.0 for Windows (IBM Japan, Ltd., Tokyo, Japan). All data were presented as the mean and standard errors (SE). After verification of a normal distribution, a one-way analysis of variance (ANOVA) followed by the Tukey multiple-comparisons procedure was used to compare means of the four groups. $p$ values less than 0.05 were considered significant.

\section{Result}

\subsection{Weight Gain, Food and Water Intake, Food Efficiency Ratio}

There were no significant differences $(p>0.05)$, due to XOS, in the average weight gained or the average final weight among the groups for all mice combined (Table 1). Moreover, no significant changes $(p>0.05)$ in food and water intake or FERs were observed.

Table 1. Weight Gain, Food and Water Intake, and FER of all mice fed different levels of XOS (Mean values and standard errors; $n=8$ in each group).

\begin{tabular}{cccccccccc}
\hline \multirow{2}{*}{ Variables } & \multicolumn{2}{c}{$\mathbf{0} \%$ XOS } & \multicolumn{2}{c}{$\mathbf{1 \%}$ XOS } & \multicolumn{2}{c}{$\mathbf{2 \%}$ XOS } & \multicolumn{2}{c}{$\mathbf{4} \%$ XOS } \\
\cline { 2 - 9 } & Mean & SE & Mean & SE & Mean & SE & Mean & SE \\
\hline FI (g/day) & 6.96 & 0.05 & 6.93 & 0.07 & 6.91 & 0.05 & 6.93 & 0.10 \\
WI (mL/day) & 5.96 & 0.07 & 5.98 & 0.14 & 5.94 & 0.16 & 5.85 & 0.12 \\
IBW (g) & 21.38 & 0.08 & 21.25 & 0.10 & 21.99 & 0.13 & 21.44 & 0.13 \\
FBW (g) & 29.04 & 0.68 & 28.99 & 0.71 & 29.65 & 0.67 & 29.13 & 0.60 \\
BG (g) & 7.66 & 0.24 & 7.74 & 0.16 & 7.66 & 0.20 & 7.69 & 0.24 \\
FERs (\%) & 3.67 & 0.03 & 3.72 & 0.02 & 3.70 & 0.01 & 3.70 & 0.01 \\
\hline
\end{tabular}

$\mathrm{SE}$, standard error; FI, food intake; WI, water intake; IBW, initial bodyweight; FBW, final bodyweight; BG, bodyweight gain; FERs, food efficiency ratios. no superscript letter $=$ no significance.

\subsection{Cecum $\mathrm{pH}$ and Cecum Wall Weight}

A significant $(p=0.005)$ and dose-dependent decrease in cecum $\mathrm{pH}$ were observed (Table 2). This decrease was accompanied by a dose-dependent increase in cecum wall weight, but only a significant difference $(p=0.01)$ was observed in $4 \%$ XOS compared to group 1 without XOS. 
Table 2. Cecum pH, Cecum Wall Weight, and Serum Ca and P Concentrations of 58-d mice fed different levels of XOS (Mean values and standard errors; $n=8$ in each group).

\begin{tabular}{ccccccccc}
\hline \multirow{2}{*}{ Variables } & \multicolumn{2}{c}{$\mathbf{0 \%}$ XOS } & \multicolumn{2}{c}{$\mathbf{1 \%}$ XOS } & \multicolumn{2}{c}{$\mathbf{2 \%}$ XOS } & \multicolumn{2}{c}{$\mathbf{4 \%}$ XOS } \\
\cline { 2 - 9 } & Mean & SE & Mean & SE & Mean & SE & Mean & SE \\
\hline Cecum pH & $7.29^{\mathrm{a}}$ & 0.01 & $7.11^{\mathrm{b}}$ & 0.02 & $6.95^{\mathrm{c}}$ & 0.02 & $6.82^{\mathrm{d}}$ & 0.03 \\
Cecum Wall Weight $(\mathrm{g})$ & $0.21^{\mathrm{a}}$ & 0.01 & $0.22^{\mathrm{ab}}$ & 0.01 & $0.23^{\mathrm{ab}}$ & 0.01 & $0.24^{\mathrm{b}}$ & 0.00 \\
Ca (mmol/L) & 2.17 & 0.02 & 2.19 & 0.02 & 2.11 & 0.01 & 2.11 & 0.02 \\
P (mmol/L) & 2.23 & 0.02 & 2.21 & 0.02 & 2.22 & 0.02 & 2.21 & 0.02 \\
\hline
\end{tabular}

SE, standard error; $a, b, c, d$ Mean values with unlike superscript letters within the same row are significantly different $(p<0.05$; Tukey post hoc test).

\subsection{Serum $C a$ and $P$ Concentration}

No significant $(p>0.05)$ differences were found at 58 -d between all groups when the serum Ca and $\mathrm{P}$ concentrations were analyzed (Table 2).

\subsection{Bone Analysis}

No significant differences $(p>0.05)$ among groups in the length, weight, or diameter of the middle axis of the femur were observed in the different stages of growth (Table 3). Though the BMD of the whole and distal femur determined via DEXA in all XOS groups showed a dose-dependent increase in the three stages of growth, a significant difference $(p=0.04)$ was seen only in the distal femur BMD between $0 \%$ XOS and $4 \%$ XOS in the period of later growth. Supplementation of different doses of XOS had no significant effect on femoral BMC in mice during different growth periods (Table S1). Meanwhile, the bone breaking strength of the $4 \%$ XOS group was significantly higher $(p=0.008)$ when compared to the $0 \%$ XOS group in the late growth stage.

Table 3. Femoral parameters, mineral density, breaking strength, and FWHM of 960/cm peak of 38, 48, and 58-d mice fed different levels of XOS (Mean values and standard errors; $n=8$ in each group).

\begin{tabular}{|c|c|c|c|c|c|c|c|c|c|}
\hline \multirow{2}{*}{ Variables } & \multirow{2}{*}{ Age (day) } & \multicolumn{2}{|c|}{$0 \%$ XOS } & \multicolumn{2}{|c|}{$1 \%$ XOS } & \multicolumn{2}{|c|}{$2 \% \mathrm{XOS}$} & \multicolumn{2}{|c|}{$4 \%$ XOS } \\
\hline & & Mean & SE & Mean & SE & Mean & SE & Mean & SE \\
\hline \multirow{3}{*}{$\begin{array}{l}\text { Bone length } \\
\quad(\mathrm{mm})\end{array}$} & 38 & 13.89 & 0.14 & 13.83 & 0.12 & 13.89 & 0.12 & 13.74 & 0.14 \\
\hline & 48 & 14.73 & 0.13 & 14.57 & 0.13 & 14.70 & 0.15 & 14.74 & 0.16 \\
\hline & 58 & 14.80 & 0.11 & 15.04 & 0.12 & 15.05 & 0.35 & 15.13 & 0.18 \\
\hline \multirow{3}{*}{$\begin{array}{c}\text { Bone weight } \\
(\mathrm{g})\end{array}$} & 38 & 0.54 & 0.01 & 0.53 & 0.00 & 0.55 & 0.00 & 0.60 & 0.01 \\
\hline & 48 & 0.64 & 0.01 & 0.60 & 0.02 & 0.57 & 0.00 & 0.60 & 0.01 \\
\hline & 58 & 0.61 & 0.02 & 0.63 & 0.00 & 0.61 & 0.00 & 0.58 & 0.01 \\
\hline \multirow{3}{*}{$\begin{array}{l}\text { Bone diameter } \\
\qquad(\mathrm{mm})\end{array}$} & 38 & 1.23 & 0.04 & 1.26 & 0.05 & 1.30 & 0.06 & 1.42 & 0.03 \\
\hline & 48 & 1.36 & 0.07 & 1.42 & 0.04 & 1.41 & 0.05 & 1.47 & 0.02 \\
\hline & 58 & 1.42 & 0.04 & 1.43 & 0.03 & 1.44 & 0.03 & 1.47 & 0.02 \\
\hline \multirow{3}{*}{$\begin{array}{l}\text { Bone breaking } \\
\text { strength }(\mathrm{N})\end{array}$} & 38 & 18.87 & 0.59 & 18.43 & 1.00 & 18.97 & 1.12 & 18.94 & 0.88 \\
\hline & 48 & 20.32 & 0.64 & 19.89 & 1.09 & 21.35 & 0.64 & 22.70 & 1.23 \\
\hline & 58 & $20.71^{a}$ & 0.28 & $21.45^{\mathrm{ab}}$ & 0.61 & $22.04^{\mathrm{ab}}$ & 0.71 & $23.29^{b}$ & 0.40 \\
\hline \multirow{3}{*}{$\begin{array}{l}\text { Femur BMD } \\
\left(\mathrm{mg} / \mathrm{cm}^{2}\right)\end{array}$} & 38 & 92.65 & 3.14 & 90.77 & 2.11 & 95.55 & 3.90 & 95.00 & 3.54 \\
\hline & 48 & 102.08 & 2.45 & 105.45 & 3.38 & 106.67 & 3.13 & 111.88 & 3.47 \\
\hline & 58 & 110.52 & 3.50 & 112.14 & 4.01 & 113.91 & 2.17 & 119.55 & 1.25 \\
\hline \multirow{3}{*}{$\begin{array}{c}\text { Distal femur } \\
\text { BMD }\left(\mathrm{mg} / \mathrm{cm}^{2}\right)\end{array}$} & 38 & 104.77 & 2.31 & 108.36 & 3.94 & 107.05 & 3.24 & 110.97 & 6.47 \\
\hline & 48 & 122.27 & 4.38 & 118.68 & 3.97 & 122.97 & 4.40 & 134.68 & 3.24 \\
\hline & 58 & $123.85^{\mathrm{a}}$ & 2.17 & $132.03^{\mathrm{ab}}$ & 6.24 & $133.43^{\mathrm{ab}}$ & 4.83 & $145.10^{b}$ & 5.83 \\
\hline \multirow{3}{*}{ FWHM } & 38 & 17.52 & 0.37 & 17.63 & 0.42 & 16.63 & 0.20 & 16.43 & 0.19 \\
\hline & 48 & 15.88 & 0.39 & 15.92 & 0.47 & 15.36 & 0.04 & 15.82 & 0.36 \\
\hline & 58 & $16.74^{\mathrm{a}}$ & 0.15 & $16.12^{a b}$ & 0.23 & $16.06^{\mathrm{ab}}$ & 0.30 & $15.39^{b}$ & 0.17 \\
\hline
\end{tabular}

SE, standard error; BMD, bone mineral density, FWHM, full width at half maximum ${ }^{\text {a }}$ b Mean values with unlike superscript letters within the same row are significantly different $(p<0.05$; Tukey post hoc test); no letter $=$ no significant. 
Raman spectroscopy was performed on the femurs of all mice. The $960 / \mathrm{cm}$ peak is commonly regarded as a measure of bone phosphate content [21,22]. The full width at half maximum (FWHM) of the $960 / \mathrm{cm}$ peak indicates the degree of atomic order in the crystallites, with wider peaks reflecting more atomically disordered materials [23,24]. The 960/cm FWHM of group 4 at 58-d was significantly $(p=0.007)$ lower than that of group 1 without XOS, and no significant difference was observed in the other groups $(p>0.05)$. However, at 38 and 48 days, the 960/cm FWHM in all groups showed no significant $(p>0.05)$ differences (Table 3).

\subsection{Gut Morphological Evaluation and Immunohistochemistry Analysis}

Duodenum tissue slices were used for morphological observations. As the drinking XOS concentration increased, the villus height of the duodenum showed a linear increase (Table 4 ). However, only $4 \%$ XOS reached statistical significance $(p<0.001, p=0.001$, and $p=0.008$, respectively) compared with $0 \%$, $1 \%$, and $2 \%$ XOS. Meanwhile, a dose-dependent decrease in crypt depth was observed (Table 4 ), and a significant increase was only observed between the $\% \%$ XOS and $4 \%$ XOS groups $(p=0.006)$. Naturally, the change in VH:CD was consistent with the intestinal villus height and crypt depth. The use of $4 \%$ XOS significantly increased the VH:CD compared to $0 \%$ XOS and $1 \%$ XOS ( $p=0.001$ and $p=0.004$, respectively).

Table 4. Duodenum morphological measurement of 58-d mice fed different levels of XOS (Mean values and standard errors; $n=8$ in each group).

\begin{tabular}{ccccccccc}
\hline \multirow{2}{*}{ Variables } & \multicolumn{2}{c}{$\mathbf{0 \%}$ XOS } & \multicolumn{2}{c}{$\mathbf{1 \%}$ XOS } & \multicolumn{2}{c}{ 2\% XOS } & \multicolumn{2}{c}{$4 \%$ XOS } \\
\cline { 2 - 9 } & Mean & SE & Mean & SE & Mean & SE & Mean & SE \\
\hline Intestinal villus height & $568.89^{\mathrm{a}}$ & 17.85 & $587.21^{\mathrm{a}}$ & 18.87 & $612.13^{\mathrm{a}}$ & 25.20 & $699.23^{\mathrm{b}}$ & 24.88 \\
Crypt depth & $90.80^{\mathrm{a}}$ & 5.74 & $82.70^{\mathrm{ab}}$ & 4.11 & $77.91^{\mathrm{ab}}$ & 4.14 & $71.41^{\mathrm{b}}$ & 2.51 \\
VH:CD & $6.58^{\mathrm{a}}$ & 0.32 & $7.19^{\mathrm{a}}$ & 0.31 & $7.98^{\mathrm{ab}}$ & 0.38 & $9.28^{\mathrm{b}}$ & 0.49 \\
\hline
\end{tabular}

SE, standard error; $\mathrm{VH}: \mathrm{CD}$, villus height: crypt depth. ${ }^{\mathrm{a}, \mathrm{b}}$ Mean values with unlike superscript letters within the same row are significantly different $(p<0.05$; Tukey post hoc test).

Immunohistochemistry assays and semi-quantitative analyses were performed to evaluate the protein expression of TRPV6 and NCX1 in the duodenum of all 58-d mice (Figure 1). Positive staining with NCX1 was observed in all groups. Compared with the control group without XOS, the 1\%, 2\%, and $4 \%$ XOS groups all had upregulated expression of NCX1, but a significant increase was only observed between the control and $4 \%$ XOS group $(p=0.01)$. Meanwhile, the expression of TRPV6 in the $1 \%, 2 \%$, and $4 \%$ XOS group mice was significantly higher than the expression in the control group $(p=0.02, p=0.03$, and $p=0.04$, respectively), while there was no significant difference found among the three groups: $1 \%, 2 \%$, and $4 \%$ XOS $(p>0.05)$.

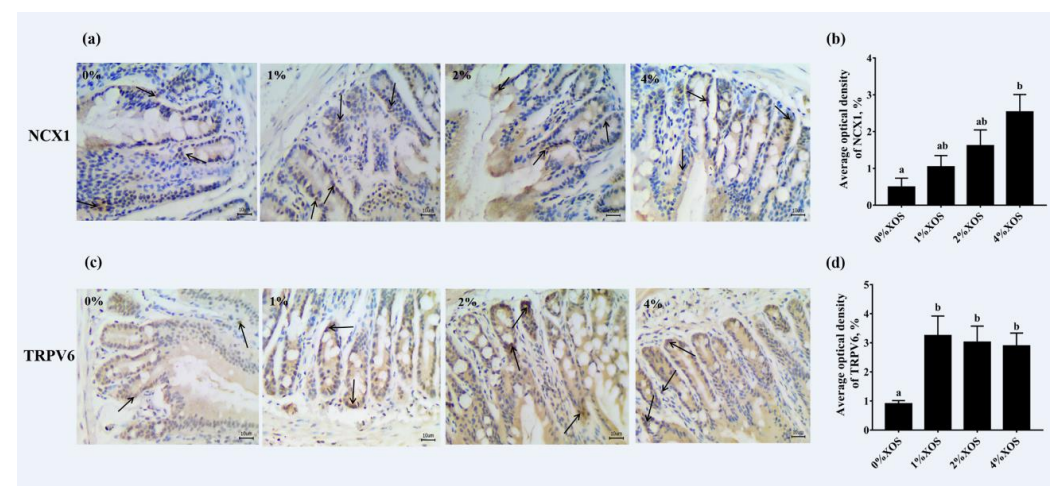

Figure 1. Effects of xylo-oligosaccharides (XOS) supplementation on the $\mathrm{Na}^{+} / \mathrm{Ca}^{2+}$ exchanger 1 (NCX1) $(\mathbf{a}, \mathbf{b})$ and transient receptor potential vanillin receptor 6 (TRPV6) (c,d) expression in the duodenum of the four groups. Scale bar: $10 \mu \mathrm{m}$. Values are means (n 8) with their standard errors represented by vertical bars. ${ }^{a, b}$ Mean values with unlike letters were significantly different $(p<0.05$; Tukey post hoc test). 


\section{Discussion}

Although the effects of several types of NDOs, such as GOS and FOS, on mineral absorption, intestinal parameters, and bone health have been reported [25-28], little is known about the effect of XOS supplementation on the potential role of bone and related calcium transporters. The rodent model used to conduct the present study showed that XOS has a positive effect on bone parameters, especially during later growth. Moreover, the greatest benefits to bone properties from XOS consumption were observed at levels of $4 \%$.

In this study, no significant changes in growth performance-related parameters were seen in the four dose-gradient groups. Indeed, irrespective of the XOS concentration in the drinking water, the food consumption, efficiency, and bodyweight gains were similar in all groups, due to eating the same isocaloric diet. Moreover, XOS supplementation did not affect the water intake of mice, and there were no significant differences among groups. The effect of XOS supplementation on growth performance was not the focus of this trial, and the results were as varied as most other NDOs indicate. In addition, XOS also had no effect on serum calcium and phosphorus concentrations because calcium and phosphorus metabolism are regulated and controlled by multiple hormones in the body.

Unsurprisingly, XOS supplementation exerted significant effects on both cecum $\mathrm{pH}$ and cecum wall weight in a dose-dependent manner, similar to other NDOs [29,30]. The decrease in cecum $\mathrm{pH}$, possibly due to the production of SCFAs, created a more acidic environment for the intestinal cavity [31,32]. This acidic environment was more conducive to improving the solubility of minerals, thereby increasing the absorption of minerals. In addition, the weight gain of the cecum wall may indirectly result from the presence of SCFAs, since butyrate is reported to be one of the primary energy sources for intestinal epithelial cells $[18,33,34]$. The production of SCFA and its nutritional effect on cecum cell proliferation were not evaluated in the present report. However, intestinal mucosal morphometry was evaluated in this study, including intestinal villus height, crypt depth, and VH:CD. XOS supplementation significantly increased the height of the duodenal villus, decreased the crypt depth, and naturally also increased the VH:CD, which indicates that the duodenal absorption area increased. This increase in the absorption surface area contributed to the absorption of minerals in the intestine. Similar to our results, some reports indicated that the duodenal villus height and crypt depth are also affected by XOS supplementation in chickens $[13,35]$. Because of the scarcity of available reports on the effects of XOS on villus height and crypt depth in rodent models, a comparison was made with other studies that used similar functional oligosaccharides. Although it was reported that NDOs undergo fermentation via intestinal microbiota in the lower intestine, Darío Pérez-Conesa et al. [36] observed that no test diet significantly modified the crypt depth or cell density in the cecum via GOS or synbiotics. Due to the dominance of the small intestine in digestion and absorption, alongside the non-influence of GOS on cecal morphometry, the focus of this trial was shifted to the duodenum. The duodenum is the main site for the transcellular transport of $\mathrm{Ca}^{2+}$ [37]. The expression of related calcium transporters in the duodenum was analyzed by immunohistochemistry in this test. Compared with $0 \%$ XOS, $4 \%$ XOS supplementation significantly enhanced the expression of NCX1, while $1 \%$ and $2 \%$ versus $0 \%$ XOS did not achieve a statistical difference. By contrast, the expression of TRPV6 in $1 \%, 2 \%$, and $4 \%$ XOS was greater than that of in $0 \%$ XOS. Hence, XOS likely upregulated the calcium transporters, such as NCX1 and TRPV6, in the active transcellular pathway of $\mathrm{Ca}^{2+}$, thereby promoting calcium absorption.

The observed effects on cecal wall weight and $\mathrm{pH}$, intestinal mucosal morphology, and calcium transporters indirectly suggest that all the above mechanisms were likely involved in the improvement of bone properties found in the present study. The positive effects of XOS supplementation on mineral absorption possibly contributed to an increase in Ca bioavailability. The increase in Ca absorption efficiency provided an extra supply of minerals, the main inorganic components of bone, inducing a beneficial increase in almost all the studied bone parameters associated with bone quality. Human bone mineral content is closely related to bone strength and internal environmental stability, so BMD is considered an important index to evaluate human health. The accurate content of bone minerals 
(mainly calcium) obtained directly plays an important role in judging and studying skeletal physiology, pathology, and human aging, as well as in diagnosing various diseases of the whole body [38]. Although the femur BMD increased in a dose-dependent manner with XOS intervention, no statistically significant difference was observed in any groups. Indeed, the specific bone sites that benefitted most had higher amounts of trabecular bone, which is metabolically more active than cortical bone (that is, the distal femur). Of course, the BMD of the distal femur by DEXA was positively influenced by $4 \%$ XOS in this study. In addition, at the midshaft femur, the breaking strength was improved by XOS. Similarly, the greatest benefit was seen with $4 \%$ XOS treatment. The strength of the newly formed bone depends on the architectural disposition of bone material, as well as other factors that are unrelated to mineralization, such as crystal arrangement and size [39]. Raman spectroscopy can be used to assess the chemical properties of minerals and organic molecules, such as measuring mineral crystallinity, and 960/cm FWHM are often used to investigate mineral crystallinity, where the wider the peak is, the more atomically disordered the material is [40]. Similar to the breaking strength, femoral mineral crystallinity benefitted most in 4\% XOS group. Moreover, it was not unexpected that the studied bone parameters enhanced significantly in the period of later growth because of the longer duration of administration [17].

In conclusion, XOS supplemental exerted a positive effect on bone properties, possibly induced by cecal wall weight and $\mathrm{pH}$, intestinal mucosal morphology, and related calcium transporters. Hence, an appropriate dose of XOS can be regarded as a promising adjunct strategy for teenagers to achieve peak bone mass.

Supplementary Materials: The following are available online at http://www.mdpi.com/2072-6643/12/11/3542/s1. Table S1: Bone mineral content (BMC) of 38, 48, and 58 days mice fed different levels of XOS (mean values and standard errors; $n=8$ in each group).

Author Contributions: The authorship of this manuscript received the following contributions: Z.Z. designed and coordinated the study. H.G. was responsible for animals feeding, the data collection, analysis and drafted manuscript. All authors contributed to reviewing and revising manuscript. All authors have read and agreed to the published version of the manuscript.

Funding: This work was supported by National Natural Science Foundation of China (No. 31572579) and a project funded by the Priority Academic Program Development of Jiangsu Higher Education Institutions (PAPD).

Conflicts of Interest: The authors have no conflict of interest.

$\begin{array}{ll}\text { Abbreviations } \\ \text { BMD } & \text { bone mineral density } \\ \text { BMC } & \text { bone mineral content } \\ \text { Ca } & \text { calcium } \\ \mathrm{Ca}^{2+} & \text { calcium ion } \\ \text { FOS } & \text { fructooligosaccharide } \\ \text { FWHM } & \text { full width at half maximum } \\ \text { GOS } & \text { galactooligosaccharide } \\ \text { HFD } & \text { High-fat diet } \\ \text { HMO } & \text { human milk oligosaccharides } \\ \text { ICR } & \text { Institute Cancer Research } \\ \text { NCX1 } & \text { Na }{ }^{+} / \text {Ca } \\ \text { NDOs } & \text { non-digestible oligosaccharides } \\ \text { P } & \text { phosphorus } \\ \text { SCFAs } & \text { short-chain fatty acids } \\ \text { TRPV6 } & \text { transient receptor potential vanillin receptor } 6 \\ \text { VH:CD } & \text { villus height to crypt depth } \\ \text { XOS } & \text { xylo-oligosaccharides }\end{array}$




\section{References}

1. Paschalis, E.P.; Gamsjaeger, S.; Hassler, N.; Fahrleitner-Pammer, A.; Dobnig, H.; Stepan, J.J.; Pavo, I.; Eriksen, E.F.; Klaushofer, K. Vitamin D and calcium supplementation for three years in postmenopausal osteoporosis significantly alters bone mineral and organic matrix quality. Bone 2017, 95, 41-46. [CrossRef] [PubMed]

2. Krupa-Kozak, U.; Markiewicz, L.; Lamparski, G.; Juśkiewic, J. Administration of Inulin-Supplemented Gluten-Free Diet Modified Calcium Absorption and Caecal Microbiota in Rats in a Calcium-Dependent Manner. Nutrients 2017, 9, 702. [CrossRef] [PubMed]

3. Seijo, M.; Bryk, G.; Zeni Coronel, M.; Bonanno, M.; Río, M.E.; Pita Martín de Portela, M.L.; Zeni, S.N. Effect of Adding a Galacto-Oligosaccharides/Fructo-Oligosaccharides (GOS/FOS ${ }^{\circledR}$ ) Mixture to a Normal and Low Calcium Diet, on Calcium Absorption and Bone Health in Ovariectomy-Induced Osteopenic Rats. Calcif. Tissue Int. 2019, 104, 301-312. [CrossRef] [PubMed]

4. Liu, J.; Tang, J.; Li, X.; Yan, Q.; Ma, J.; Jiang, Z. Curdlan (Alcaligenes faecalis) (1 $\rightarrow 3$ )- $\beta$-d-Glucan Oligosaccharides Drive M1 Phenotype Polarization in Murine Bone Marrow-Derived Macrophages via Activation of MAPKs and NF-kB Pathways. Molecules 2019, 24, 4251. [CrossRef] [PubMed]

5. Tanabe, K.; Nakamura, S.; Moriyama-Hashiguchi, M.; Kitajima, M.; Ejima, H.; Imori, C.; Oku, T. Dietary Fructooligosaccharide and Glucomannan Alter Gut Microbiota and Improve Bone Metabolism in Senescence-Accelerated Mouse. J. Agric. Food Chem. 2019, 67, 867-874. [CrossRef] [PubMed]

6. Gibson, G.R.; Hutkins, R.; Sanders, M.E.; Prescott, S.L.; Reimer, R.A.; Salminen, S.J.; Scott, K.; Stanton, C.; Swanson, K.S.; Cani, P.D. Expert consensus document: The International Scientific Association for Probiotics and Prebiotics (ISAPP) consensus statement on the definition and scope of prebiotics. Nat. Rev. Gastroenterol. Hepatol. 2017, 14, 491-502. [CrossRef]

7. Kivit, S.D.; Kostadinova, A.I.; Kerperien, J.A.; Morgan, M.E.; Willemsen, L.E.M. Dietary, nondigestible oligosaccharides and Bifidobacterium breve M-16V suppress allergic inflammation in intestine via targeting dendritic cell maturation. J. Leukoc. Biol. 2017, 102, 105-115. [CrossRef]

8. Laura, W.; Marianne, B.S.; Giulio, G.; Vonk, M.M.; Van, E.B.C.A.M.; Knippels, L.M.J.; Johan, G.; Smit, J.J.; Pieters, R.H.H. Dietary Supplementation with Non-Digestible Oligosaccharides Reduces Allergic Symptoms and Supports Low Dose Oral Immunotherapy in a Peanut Allergy Mouse Model. Mol. Nutr. Food Res. 2018, 62, e1800369.

9. Okazaki, Y.; Katayama, T. Consumption of non-digestible oligosaccharides elevates colonic alkaline phosphatase activity by up-regulating the expression of IAP-I, with increased mucins and microbial fermentation in rats fed a high-fat diet. Br. J. Nutr. 2019, 121, 146-154. [CrossRef]

10. Vázquez, M.J.; Alonso, J.L.; Domínguez, H.; Parajó, J.C. Xylooligosaccharides: Manufacture and applications. Trends Food Sci. Technol. 2000, 11, 387-393. [CrossRef]

11. Moure, A.; Gullón, P.; Domínguez, H.; Parajó, J.C. Advances in the manufacture, purification and applications of xylo-oligosaccharides as food additives and nutraceuticals. Process Biochem. 2006, 41, 1913-1923. [CrossRef]

12. Ribeiro, T.; Cardoso, V.; Ferreira, L.M.A.; Lordelo, M.M.S.; Coelho, E.; Moreira, A.S.P.; Domingues, M.R.M.; Coimbra, M.A.; Bedford, M.R.; Fontes, C.M.G.A. Xylo-oligosaccharides display a prebiotic activity when used to supplement wheat or corn-based diets for broilers. Poult. Sci. 2018, 97, 4330-4341. [CrossRef] [PubMed]

13. Ding, X.M.; Li, D.D.; Bai, S.P.; Wang, J.P.; Zeng, Q.F.; Su, Z.W.; Xuan, Y.; Zhang, K.Y. Effect of dietary xylooligosaccharides on intestinal characteristics, gut microbiota, cecal short-chain fatty acids, and plasma immune parameters of laying hens. Poult. Sci. 2017, 97, 874-881. [CrossRef] [PubMed]

14. Pan, J.; Yin, J.; Zhang, K.; Xie, P.; Kong, X. Dietary xylo-oligosaccharide supplementation alters gut microbial composition and activity in pigs according to age and dose. AMB Express 2019, 9, 134. [CrossRef] [PubMed]

15. Whisner, C.M.; Castillo, L.F. Prebiotics, Bone and Mineral Metabolism. Calcif. Tissue Int. 2018, 102, 443-479. [CrossRef]

16. Thiennimitr, P.; Yasom, S.; Tunapong, W.; Chunchai, T.; Wanchai, K.; Pongchaidecha, A.; Lungkaphin, A.; Sirilun, S.; Chaiyasut, C.; Chattipakorn, N.; et al. Lactobacillus paracasei HII01, xylooligosaccharides and synbiotics reduced gut disturbance in obese rats. Nutrition 2018, 54, 40-47. [CrossRef] 
17. Wang, S.; Zhang, P.; Kong, X.; Xie, S.; Li, Q.; Li, Z.; Zhou, Z. Delicate changes of bioapatite mineral in pig femur with addition of dietary xylooligosaccharide: Evidences from Raman spectroscopy and ICP. Anim. Sci. J. 2017, 88, 1820-1826. [CrossRef]

18. Raschka, L.; Daniel, H. Mechanisms underlying the effects of inulin-type fructans on calcium absorption in the large intestine of rats. Bone 2005, 37, 728-735. [CrossRef]

19. Mineo, H.; Hara, H.; Tomita, F. Short-chain fatty acids enhance diffusional Ca transport in the epithelium of the rat cecum and colon. Life Sci. 2001, 69, 517-526. [CrossRef]

20. Ohta, A.; Motohashi, Y.; Sakai, K.M. Dietary fructooligosaccharides increase calcium absorption and levels of mucosal calbindin-D9k in the large intestine of gastrectomized rats. Scand. J. Gastroenterol. 1998, 33, 1062-1068.

21. Pascart, T.; Cortet, B.; Olejnik, C.; Paccou, J.; Migaud, H.; Cotton, A.; Delannoy, Y.; During, A.; Hardouin, P.; Penel, G.; et al. Bone Samples Extracted from Embalmed Subjects Are Not Appropriate for the Assessment of Bone Quality at the Molecular Level Using Raman Spectroscopy. Anal. Chem. 2016, 88, 2777-2783. [CrossRef] [PubMed]

22. Awonusi, A.; Morris, M.D.; Tecklenburg, M.M.J. Carbonate Assignment and Calibration in the Raman Spectrum of Apatite. Calcif. Tissue Int. 2007, 81, 46-52. [CrossRef] [PubMed]

23. Carden, A.; Morris, M.D. Application of vibrational spectroscopy to the study of mineralized tissues (review). J. Biomed. Opt. 2000, 5, 259-268. [CrossRef] [PubMed]

24. Mandair, G.S.; Morris, M.D. Contributions of Raman spectroscopy to the understanding of bone strength. Bonekey Rep. 2015, 4, 620. [CrossRef] [PubMed]

25. Bryk, G.; Coronel, M.Z.; Pellegrini, G.; Mandalunis, P.; Rio, M.E.; De Portela, M.L.P.M.; Zeni, S.N. Effect of a combination GOS/FOS prebiotic mixture and interaction with calcium intake on mineral absorption and bone parameters in growing rats. Eur. J. Nutr. 2015, 54, 913. [CrossRef]

26. Weaver, C.M.; Martin, B.R.; Nakatsu, C.H.; Armstrong, A.P.; Clavijo, A.; Mccabe, L.D.; Mccabe, G.P.; Duignan, S.; Schoterman, M.H.C.; van den Heuvel, E.G.H.M. Galactooligosaccharides improve mineral absorption and bone properties in growing rats through gut fermentation. J. Agric. Food Chem. 2011, 59, 6501-6510. [CrossRef]

27. Demigné, C.; Jacobs, H.; Moundras, C.; Davicco, M.J.; Horcajada, M.-N.; Bernalier, A.; Coxam, V. Comparison of native or reformulated chicory fructans, or non-purified chicory, on rat cecal fermentation and mineral metabolism. Eur. J. Nutr. 2008, 47, 366-374. [CrossRef]

28. Lobo, A.R.; Filho, J.M.; Alvares, E.P.; Cocato, M.L.; Colli, C. Effects of dietary lipid composition and inulin-type fructans on mineral bioavailability in growing rats. Nutrition 2009, 25, 216-225. [CrossRef]

29. Christensen, E.; Licht, T.; Leser, T.; Bahl, M. Dietary Xylo-oligosaccharide stimulates intestinal bifidobacteria and lactobacilli but has limited effect on intestinal integrity in rats. BMC Res. Notes 2014, 7, 1-14. [CrossRef]

30. Lecerf, J.M.; Dépeint, F.; Clerc, E.; Dugenet, Y.; Niamba, C.N.; Rhazi, L.; Cayzeele, A.; Abdelnour, G.; Jaruga, A.; Younes, H.; et al. Xylo-oligosaccharide (XOS) in combination with inulin modulates both the intestinal environment and immune status in healthy subjects, while XOS alone only shows prebiotic properties. Br. J. Nutr. 2012, 108, 1847-1858. [CrossRef]

31. Johnson, C.D.; Lucas, E.A.; Hooshmand, S.; Campbell, S.; Arjmandi, B.H. Addition of Fructooligosaccharides and Dried Plum to Soy-Based Diets Reverses Bone Loss in the Ovariectomized Rat. Evid. Based Complement. Alternat. Med. 2010, 2011, 836267. [CrossRef] [PubMed]

32. Rodrigues, F.C.; Castro, A.S.; Rodrigues, V.C.; Fernandes, S.A.; Fontes, E.A.; de Oliveira, T.T.; Martino, H.S. Yacon Flour and Bifidobacterium longum Modulate Bone Health in Rats. J. Med. Food 2012, 15, 664-670. [CrossRef] [PubMed]

33. Yang, L.C.; Wu, J.B.; Lu, T.J.; Lin, W.C. The prebiotic effect of Anoectochilus formosanus and its consequences on bone health. Br. J. Nutr. 2013, 109, 1779-1788. [CrossRef] [PubMed]

34. García-Vieyra, M.I.; Del Real, A.; López, M.G. Agave fructans: Their effect on mineral absorption and bone mineral content. J. Med. Food 2014, 17, 1247-1255. [CrossRef]

35. Suo, H.Q.; Lin, L.U.; Guo-Hui, X.U.; Lin, X.; Chen, X.G.; Xia, R.R.; Zhang, L.Y.; Luo, X.G. Effectiveness of dietary xylo-oligosaccharides for broilers fed a conventional corn-soybean meal diet. J. Integr. Agric. 2015, 14, 2050-2057. [CrossRef]

36. Pérez-Conesa, D.; López, G.; Ros, G. Effect of probiotic prebiotic and synbiotic follow-up infant formulas on large intestine morphology and bone minerlisation in rats. J. Ence Food Agric. 2007, 87, 1059-1068. [CrossRef]

37. Barboza, G.D.D.; Guizzardi, S.; Talamoni, N.T.D.; Molecular, C.D.B.Y.B.; Médicas, F.D.C.; Córdoba, U.N.D. Molecular aspects of intestinal calcium absorption. World J. Gastroenterol. 2015, 21, 7142-7154. [CrossRef] 
38. Glimcher, M.J. Bone: Nature of the Calcium Phosphate Crystals and Cellular, Structural, and Physical Chemical Mechanisms in Their Formation. Rev. Mineral. Geochem. 2006, 64, 223-282. [CrossRef]

39. Burr, D.B.; Robling, A.G.; Turner, C.H. Effects of biomechanical stress on bones in animals. Bone 2002, 30, 781-786. [CrossRef]

40. Li, Z;; Pasteris, J.D. Tracing the pathway of compositional changes in bone mineral with age: Preliminary study of bioapatite aging in hypermineralized dolphin's bulla. BBA Gen. Subj. 2014, 1840, 2331-2339. [CrossRef]

Publisher's Note: MDPI stays neutral with regard to jurisdictional claims in published maps and institutional affiliations.

(C) 2020 by the authors. Licensee MDPI, Basel, Switzerland. This article is an open access article distributed under the terms and conditions of the Creative Commons Attribution (CC BY) license (http://creativecommons.org/licenses/by/4.0/). 